\title{
Becoming Globally Literate: Teaching Cross-Cultural Awareness Through The Use Of Social Networking Sites
}

Kenneth T. Carano, University of South Florida, USA

\begin{abstract}
The digital era has enabled educators the opportunity of breaking the confinement of the four walls of the traditional classroom and accessing information across cultures and nations. This session discusses the implementation of an innovative online graduate teacher education course focusing on global perspectives. Over the course of the semester, teachers learn how to use social networking sites as a means of gaining tools to cultivate a greater understanding of their own stereotypes and prejudices while learning how to enhance the global literacy of themselves and others. In addition, through the creative nature of blogging, this course provides strategies for teachers to draw on personal experiences as they develop their own network of classroom consultants, across the globe, to foster a greater level of cultural literacy in their students.
\end{abstract}

Keywords: cross-cultural awareness, global perspectives, blogs

\section{INTRODUCTION}

$\mathrm{n}$ the depths of a rain forest village, a man sitting at his trading post answers his ringing cellular phone and responds to the voice from the United States on the other end. A sixth grade class in Indiana gathers around the table in their classroom while talking on a speaker phone to a Peace Corps volunteer in South America. A woman's computer breaks and she is forced to place a call from the United States that will have her speaking with a technician at a call center in India to get the problem solved. A woman in the north African country of Morocco answers questions on a blog that high school students had asked in Florida.

As society embarks upon the 21st century, the world is becoming increasingly interconnected. Many decisions we make and actions we take have an impact on global society. Despite the world's increasing connectedness, educational systems are not reflecting this phenomenon. The overwhelming majority of countries still emphasize nationalistic curricula (Tye, 1999). This may, in part, be due to being immersed in the localized culture. Yet, as the examples in the previous paragraph attest, in this emerging digital age, all forms of culture are shaped by global influences and the populous no longer has to be face-to-face to have a cultural exchange.

Unfortunately, at the same time we are living in a globally interconnected society and our youth are getting the majority of their "global" education from the media (Hahn, 1998). According to many teachers, this forces them to spend time guiding students to unlearn the exaggerated information they have promulgated because of media stereotypes (Seikaly, 2001). Further, often times the available textbooks have defects, such as representing a distorted view of subjects being investigated by the students (Zhao \& Hoge, 2006; Seikaly, 2001). This exasperates the problem since history textbooks have a great influence on the societal and cultural perspectives students develop (Zhao \& Hoge, 2006). As a result, it is time that global education be given a more prominent place in the curricula.

\section{IMPLEMENTING THE COURSE}

The world society has been in the process of shifting to an information age. To keep pace with this shift, many teacher education programs are attempting to update the skills of the teachers who will be using these 
techniques to shape our youth (Marra, 2004). The opportune time to influence change is when society is in transition; therefore, this new information age, aided in large part by technology, is an ideal time to introduce a course that incorporates technology to provide educators with the tools necessary for the classroom.

The use of technology has many benefits. It is advantageous for certain learning styles, such as those who express themselves more confidently through reading and writing. An online course, which includes a virtual discussion dimension, provides an opportunity for everyone to "vocalize" their opinions rather than what often occurs in a face-to-face setting where a few students dominate the dialogue. Discussions revolving around sensitive and controversial topics tend to be more productive in an online setting (Merryfield, 2000), as it is more comfortable for many students to discuss these issues online. As a result, more students develop deeper discussions and more critical thinking on an issue. On the other hand, there is a downside to an online course. The subtleties of face-toface interactions are missed (i.e. facial expressions, intonations, etc...) and it places those who prefer such interactions at a possible disadvantage. It also denies the instructor an opportunity to utilize those teachable moments that often unexpectedly arise in the classroom.

\section{The Goals}

Providing technology alone is not enough for students to become global educators. In order to further enhance their cross-cultural awareness and global literacy through the use of technology, a second remedy is necessary. Global perspectives should be incorporated into social studies programs (Carano \& Berson, 2007). To do this, this course focused on teaching students how to incorporate eight dimensions of a global perspective in their classrooms. The first five dimensions are based on the work of Robert Hanvey (1976), dimensions six and eight are components Merry Merryfield (2001) advocates should be integrated into social studies curricula, and the seventh dimension is promoted by Toni Kirkwood (2001). As will be demonstrated in the next section, technology has the capacity of enhancing each of these dimensions. An overview of the framework is provided below.

\section{Eight Dimensions of a Global Perspective}

\begin{tabular}{|ll|}
\hline (1) & Perspective Consciousness: Realize each person's world view is unique. \\
(2) & "State of the Planet" Awareness: Aware of world conditions and trends. \\
(3) & $\begin{array}{l}\text { Cross-Cultural Awareness: Perceive your culture from other vantage points. Live "in" rather } \\
\text { than "with" }\end{array}$ \\
(4) & $\begin{array}{l}\text { Knowledge of Global Dynamics: Aware world events are interconnected and have unanticipated } \\
\text { consequences. }\end{array}$ \\
(5) & Awareness of Human Choices: Realize implications of choices. \\
$(6)$ & Understanding the Marginalized Point of View. Empathy for the disenfranchised. \\
$(7)$ & $\begin{array}{l}\text { Involvement in local or global affairs: Service learning with a goal of improving the human condition. } \\
\text { (8) }\end{array}$ \\
& Analyzing the Educational Legacy of Colonialism: Analyze alternatives to Eurocentric framework of
\end{tabular} (Hanvey 1976, Merryfield, 2001, Kirkwood, 2001)

Many people in the United States have demonstrated a remarkable lack of awareness of people and places outside the immediate physical locale of their daily lives. In a recent study done by the National Geographic's Global Geographic Literacy Survey (2006), United States citizens', aged 18-24, geography and cultural skills appear to be dismally lacking. For example, despite the extensive media coverage of the overthrow of the Taliban in Afghanistan after 9/11 and the on-going United States presence in Iraq, nearly 90\% of young Americans were unable to locate Afghanistan on a map and 63\% were unable to find Iraq. Results from the previous administration of the survey in 2002 demonstrated that United States citizens were less culturally aware than comparable same-age peers from other industrialized nations (RoperASW, 2002). In addition, researchers have found people tend to individualize the characteristics of people in their in-group and perceive their behavior as normal, while viewing out-groups in terms of more stereotypical characteristics (Merryfield \& Wilson, 2005).

Robert Hanvey addressed four levels of cross-cultural awareness (dimension 3). These levels are outlined in the box below. There is much fluidity between levels I and II, with neither allowing a person to experience 
empathy with another culture, either consciously or subconsciously. According to Hanvey, true acceptance of another culture's people is only achieved at levels III and IV. While level IV is an ultimate goal, it is very difficult to attain; and level III, while not having achieved the status of an "insider", remains an attainable intellectual and practical goal for most people. As a result of the dismal showing of cross-cultural awareness outlined in the previous paragraph, this course also sought to provide students with strategies to attain higher levels of crosscultural awareness.

Levels of Cross-Cultural Awareness

\begin{tabular}{|c|c|c|c|}
\hline Level & Information & Mode & Interpretation \\
\hline I. & $\begin{array}{l}\text { awareness of superficial or visible } \\
\text { cultural traits; stereotypes }\end{array}$ & $\begin{array}{l}\text { tourism, textbooks, } \\
\text { National Geographic }\end{array}$ & $\begin{array}{l}\text { unbelievable, } \\
\text { i.e. exotic }\end{array}$ \\
\hline II. & $\begin{array}{l}\text { awareness of significant \& subtle } \\
\text { cultural traits that contrast } \\
\text { markedly with one's own }\end{array}$ & $\begin{array}{l}\text { cultural conflict } \\
\text { situations }\end{array}$ & $\begin{array}{l}\text { unbelievable, } \\
\text { i.e. frustrating }\end{array}$ \\
\hline III. & $\begin{array}{l}\text { awareness of significant \& subtle } \\
\text { cultural traits that contrast } \\
\text { with one's own }\end{array}$ & intellectual analysis & $\begin{array}{l}\text { believable, } \\
\text { cognitivity }\end{array}$ \\
\hline IV. & $\begin{array}{l}\text { awareness of how another } \\
\text { culture feels from the } \\
\text { standpoint of the insider }\end{array}$ & $\begin{array}{l}\text { cultural immersion } \\
\text { living the culture }\end{array}$ & $\begin{array}{l}\text { subjective } \\
\text { familiarity } \\
\text { Hanvey, p. 16, } 1976\end{array}$ \\
\hline
\end{tabular}

\section{THE COURSE}

Taught predominantly online, this course focused on global perspectives and how these perspectives can be facilitated through the use of technology. As a result of breaking the confinement of the four walls of the traditional classroom, students were able to consult with people and access materials globally, review changing perspectives they were developing, and explore resources and service learning opportunities across the world, regardless of the classroom locale.

\section{Participants}

Twenty-three Master's level social science education students from the University of South Florida participated in the course. In addition, five people with intimate knowledge of a culture unfamiliar to mainstream American culture participated as consultants. These participants were referred to as cultural consultants, a concept coined by Merry Merryfield (2003). They interacted with the students for a portion of the course to demonstrate the tranformatory power a cultural consultant blog can have on student stereotypes and global awareness. The consultants consisted of a Ghanaian nationalist; Surinamese nationalist; a returned Peace Corps volunteer who served in Suriname, South America, and married a Surinamese nationalist; a former Peace Corps volunteer currently living and working in Denmark; and an Asian-American lesbian.

\section{Technical Components}

The course predominantly took place within the University of South Florida blackboard system. This allowed students to discuss issues on a class blog, view instructor notes, share global dimensions activities and lesson plans, and access websites and streaming videos. When interacting with the cultural consultants, a free blog was established through wordpress.com. This was done for two reasons. First, since the cultural consultants were not affiliated with the university, they did not have access to the blackboard system. Second, by spending a portion of the course participating in such a blog, students were provided the opportunity of familiarizing themselves with a 
blog tool that allows teachers to moderate user comments. As a result, they attained experience to establish their own cultural-consultant blogs as classroom instructors.

Each week, virtual discussions were initiated by an instructor prompt that referenced the topic readings or videos. The topic discourse would take place over the course of a week, and all participants were required to post and respond to others' posts on multiple days. The number of posts each person should write during the week ranged from six to eight and was established at the beginning of each week by the instructor when the first topic prompt was posted. This format allowed readers sufficient time to read and react to each others' messages before posting additional messages.

\section{Developing the Global Dimensions \& Levels of Cross-Cultural Awareness}

Perspective consciousness, cross-cultural awareness, and understanding the marginalized point of view, each require students to explore a culture or person's experience from the perspective of the group or person who is being studied (Carano \& Berson, 2007). Researchers report that students who study cultures in this manner are less likely to have misconceptions reinforced and are more likely to appreciate that culture's point of view (Holloway 2002; Risinger 2006), which may allow students to gain a level III appreciation of cross-cultural awareness. The nature of this course allowed students to attain this level and model ways in which they can incorporate activities in their classrooms through such activities as the cultural consultant blog. For an example, see the virtual discussion dialogue between the cultural consultant and student in the Building a Community of Global Educators subsection.

Another major component of the course was the exploration of online global resources. By encouraging students to access news websites on a daily basis from around the world, teachers gained the skills and access to the sources that will enable their students to become aware of world trends and conditions, therefore meeting a key component of the "State of the Planet" awareness dimension. "Digital literacy fosters the knowledge and skills for global citizenship by linking everyday individual actions with the consequences for oneself and others" (Berson \& Berson, p. 144, 2006). As a result, incorporating technology into curricula has the ability to educate students on the knowledge of global dynamics and awareness of human choices. Throughout the course, students engaged in discussions of current events, such as the war in Iraq, and debated underlying and unanticipated consequences of these events. This provided a model of the discourse necessary in developing analyzing and synthesizing skills, necessary components of the two preceding global dimensions.

Students were able to gain tools for the seventh global dimension, involvement in local or global affairs, by being exposed to online resources encouraging service learning. The Internet has provided youth the opportunity to greatly enhance their engagement in global and community affairs. In a study done by the Center for Social Media at American University, more than 400 websites dedicated to youth civic engagement were identified (Montgomery, Gottlieb-Robles, \& Larson, 2004). One such site students were exposed to, iEARN, allows United States students to collaborate with youth from around the globe to work on grass-roots projects. This site not only provides service learning opportunities, but it also is an outlet in counteracting stereotypes among youth.

Finally, the eighth dimension, analyzing the legacy of colonialism, is the process of understanding how western education is unconsciously embedded in a white-European interpretation of events and how those events are only considered "normal" from this white-European perception (Merryfield, 2001). This educational point of view has had the effect of relegating minority perspectives to be abnormal or out of the mainstream. By challenging students embedded beliefs in the virtual discussion prompts and cultural consultant discourse, course participants were forced to analyze these alternative perspectives.

\section{Community of Global Educators}

In order to build a community of global educators, a variety of methods was employed. In addition to the virtual discussions on the blogs, over the course of the semester, students were required to develop classroom activities based on each of the eight global dimensions, develop cultural-consultant blog lessons, and a global perspective lesson plan that incorporated each of the eight global dimensions. Each of these activities and lessons 
were posted on the blackboard; therefore, each student was provided the opportunity to leave the course with hundreds of free global education lessons and activities to use in their classrooms.

The virtual discussion dialogue began by providing a prompt for everyone to write and share short autobiographies that focus on their lived experience and knowledge of construction related to the course content. This initial question was asked by Dr. Merryfield at the beginning of her courses:

Write a half-page (single-spaced) description of your cultural background and identity so that everyone in the class can get a sense of who you are. Then choose three or four words you would use to identify yourself and type them in under your name and email address at the top of the page. In the next half page, describe some of what you think have been your most important experiences with people different from yourself as a child, in school and university, and as an adult. What were you taught about people different from yourself? What have you learned through actual experiences with people different from yourself? (Merryfield, p. 509, 2000)

This question jump started a dialogue between the classmates by opening each other up to each other's cultures as the following portion of an exchange between a cultural consultant and student demonstrates.

Jolanda

Open-minded, Determined, Giving, Industrious

Hello my name is Jolanda. I am from Suriname. I met my husband Jesse while he was in the Peace Corps. He lived in the village of Apoera where I grew up. I met him at my cousin's wedding. I have one daughter and we all came to the United States together in 2000. I am primarily Arawak Indian but also have some African and Indian (Hindustani) in me. I speak three languages fluently; English, Dutch and Sranan Tongo. I grew up in the village Apoera in West Suriname. Apoera was originally exclusively Native American. My parents were farmers and I am one of eight children. My parents did not put a lot of importance in education. They expected us to go to school, but did not encourage us to try to go further than the sixth grade. They were not very supportive of any of my siblings to continue our education.

Growing up in Apoera, there were only people similar to me. People were primarily Arawak and Warrow Indians, so I did not have a lot of exposure to other cultures as a young child. As I became a teenager, people of different cultural backgrounds began to move into the village of Apoera. Similar to America, Suriname is a country with people of different cultural backgrounds. You have East Indians, Indonesian, Chinese, Africans and some people of European descent. I did not have too much exposure to this until I was a teenager. When new people began to move into Apoera, the original inhabitants of Apoera did not hate the newcomers, they just did not want me or any of my sisters to date or marry an Afro-Surinamese. My dad once told me, "I don't ever want you to bring a black man home!" Lately things have changed even more in Apoera and people have become more accepting of different cultures there.

When I was fifteen, I moved from Apoera to Paramaribo, the capital city of Suriname. I stayed with my older sister, and I worked in a boutique. I met and made friends with a lot of people from different cultures. I had Indonesian, Indian, African and Chinese friends. All of these people were Surinamese, but like in the U.S., many kept large parts of their culture with them. Suriname does have its own distinct culture, but it is a mosaic like in the United States. When I think back, I never thought that the people from different cultures that I met would be so open-minded and friendly. One of my male, Afro-Surinamese friends changed my preconceived notions that I formed from what my dad said about black people. Living in the city, I began to see people more as individuals, not classified into the groups like I used to put them into.

I had my daughter when I was twenty-seven years old. Her father was not a great guy, he was physically abusive, and the relationship ended badly. We were never married. With little options after an extremely bad breakup, I moved back to Apoera and stayed with my parents. I didn't know what to do. I knew I did not want to farm, so I decided to set-up a food stand and make food like the people cooked in Paramaribo. Apoera had changed a lot since I had left. The majority of people living there were still Native American, but many people of mixed descent moved into the area. 
After my bad relationship, I thought that I would never be with anyone ever again and I would raise my daughter alone. Life has a funny way of working itself out, because a few months later I met my current husband. I never dated a white person before I met my husband. As I wrote before, he was in the Peace Corps and we began our relationship over nine years ago and we got married seven years ago. I came back to live in the United States with him and my daughter in 2000.

American culture is nice, but sometimes some things about it are very different from how I grew up. For example, in American culture, people make it a point to always apologize to each other for mistakes they made. In my culture, people rarely ever apologize to one another. They usually just get over it. I have learned to adapt and I try to remember to apologize when I am wrong to my husband and daughter. Sometimes I still don't feel comfortable with my English or I feel like people look down on me because I did not go further in my education. People seem to judge you more here for what you do. I clean houses for a living and I have had many experiences when people find out what I do, they do not make an effort to be my friend. It is difficult because I do not know many other Surinamese people in the United States, but am happy living here in the U.S. because there are more opportunity for me and my daughter. I want to go back to school, and since my husband finally finished his Masters Degree, it will be my turn.

Comment by Jolanda Longacre | June 17, 2007

Your blog was very informative Jolanda! I'm always impressed with people who know more than one language. Up until Mr. Carano had told us a bit about Suriname, I only knew its location. It sounds difficult to grow up in a culture that doesn't encourage furthering post-high school education or even a high school education. All but 2 of my 7 or so friends growing up in the Pittsburgh area of Pennsylvania had received a High School Diploma and they, like me, went on to college and grad school. My father was a teacher and he supported all of my education endeavors and still does. What program are you going to undertake at college when you attend? It seems as if you have a lot of doors open since you are extremely knowledgeable of other cultures and know 3 languages. In terms of your past relationships, I've heard similar comments in my own family. My wife is an Austrian-American (white woman) and my father never, ever seemed upset with my decisions to date white, black, and even a biracial female.... but my older sister told me what he said and it's just as you had experienced. He said, "Don't ever bring home a white boy" When she told me this, I felt nervous to disappoint him, but it sounded so ridiculous that I didn't care. My father must have felt a different way when she was growing up because he is hugs and kisses with my wife and never shows bias towards us. So basically two questions: What do you plan to study in college? Has your childrearing techniques been altered since you moved to the U.S. and if so, what ways?

Comment by Gregory Samuels | June 18, 2007

Gregory, to answer your questions:

First thing, before I go to college, I have to get my GED. I am thinking of going into a trade of some kind. I am not sure right now. I like to cook and I like sewing/designing clothes and business, but I have to figure out how I am going to choose a career that focuses on these skills. How I am raising my daughter has changed. Discipline is very different in Suriname. There is more spanking and corporal punishment. I try to avoid corporal punishment. I did not think about this as much when I was in Suriname. Also, we try to talk about our problems and make sure that we apologize to each other if someone does something wrong. Like I said before, the Amerindian culture that I grew up in does not make it a practice to apologize regularly. That has definitely changed. Also, I am making sure that my daughter takes school seriously. I am always on top of her about her homework and other assignments. My parents felt that if you failed in school, then you failed and that was it. They did not try to think of ways to help us pass if we were struggling or talk to our teachers.

Comment by Jolanda Longacre | June 19, 2007

I found it to be interesting how it was customary for Surinamese to marry at 14-15 years old. One thing that you mentioned earlier that prompted me to realize a common aspect of history is how African-Americans are viewed in the US and why. Blacks were slaves of course during "our" Civil War and the Slavery Era leading up to that and the female slaves were raped by the White slave owners. Horrible history lesson, but I mentioned it b/c it seems as if 
the Afro-Surinamese and Amerindian women had similar situations. Also, you mentioned that there is a dialect of Dutch, Africaan, Portuguese, and English which is not highly looked upon and people are trying to unlearn it basically. Don't know if this is similar to what we have in our culture, but I'll mention it because it's similar. We have a dialect of English (slang) that parents and teachers do not look upon highly. It's called "Ebonics". It's a slang used originated by Blacks, used by both Black and White people nowadays. It's broken English and sometimes even words that are made up. Kids and some adults use it around friends mostly and adults discourage it in a school-setting and at work. Has American popular culture had an impact on Paramaribo or even Apoera? Do we have similar food products, music, etc. in Paramaribo or even Apoera? What are some stereotypes (if any?) that Surinamese people have of Americans?

Comment by Gregory Samuels | June 21, 2007

To demonstrate ways students strengthened their ability to incorporate the global dimensions in their instruction, the illustration in Figure 1 from a student global dimension activity has been provided:

Global Dimensions Activity

\section{Figure 1}

\section{Activity Name: Listening to Chinua Achebe on the Radio}

Goals: Examine the perspectives on the impact of Christian (Western) culture on Nigeria

Global Dimensions Addressed: Cross-Cultural Awareness- Accessing an author from another culture is a strong way of attaining the observations of someone whose perceptions are artistic and deeper than average.

\section{Procedures:}

1. Students will listen to the excerpts on Chinua Achebe.

2. Students will answer the various questions below in groups of four, then we will discuss their findings.

\section{Questions:}

a. What values does Chinua give the English language; how is it useful? How does view the English language in relation to colonialism? What does he say about writing in African languages?

b. Examine the dual way of looking at the world: traditional religions v. Christian religion. Examine the destruction of the taboo. Why it is important to have taboos according to Chinua? What are some examples of taboos? What is anarchy? How do we view taboos in society?

c. Were children's books racist? What do the younger generation read? What kinds of themes does Chinua embrace for kids ( Beauty v books that awaken their conscious)?

d. Last question: To what extent is Chinua open to English culture? How does he introduce African culture and language into people's lives?

Necessary Materials: One computer, to listen to excerpts from this link:

http://www.bbc.co.uk/bbcfour/audiointerviews/profilepages/achebec1.shtml

\section{CONCLUSION}

While the cultural literacy of young people in the United States may be in a state of peril, educators increasingly have the tools at their disposal to alter this illiteracy. Incorporating technology and global perspectives into curricula provides the tools to alter this lack of cultural awareness while, at the same time, presenting students an interactive experience. This course, implemented at the University of South Florida, displays the exciting potential technology has to offer and demonstrates that constructing global literacy and cultural awareness is now more attainable than ever before. 


\section{AUTHOR INFORMATION}

Kenneth Carano is an adjunct instructor at the University of South Florida and a former Peace Corps volunteer, who spent two years teaching elementary students and running an after-school program in Suriname, South America. In addition to his duties at the University of South Florida, he has been a high school social studies instructor in Sarasota, Florida. Mr. Carano's research interests are global perspectives in teacher education programs and preparing students to be effective citizens in a world that is becoming increasingly interconnected.

\section{REFERENCES}

1. Berson, I. R., \& Berson, M. J. (2006) Children and their Digital Dossiers: Lessons in Privacy Rights in the Digital Age. Enhancing Democracy with Technology in the Social Studies. International Journal of Social Education 21(1), 135-147.

2. Carano, K. T., \& Berson, M. J. (2007). Breaking Stereotypes: Constructing Geographic Literacy \& Cultural Awareness through Technology. The Social Studies 98(2), 65-70.

3. Hahn, C.L. (1998). Becoming Political: Comparative perspectives on citizenship education. Albany, NY: State University of New York Press.

4. Hanvey, R. G. (1976). An Attainable Global Perspective. New York: The American Forum for Global Education.

5. Holloway, J. H. (2002). What do students know? Educational Leadership 60(2), 85- 86.

6. Kirkwood, T. F. (2001). Preparing teachers to teach from a global perspective. The Delta Kappa Gamma Bulletin 67(2), 5-12.

7. Marra, R.M. (2004). An Online Course to Help Teachers "Use Technology to Enhance Learning”: Successes and Limitations. Journal of Technology and Teacher Education 12(3), 411-429.

8. Merryfield, M. M. (2003). Like a veil: Cross-Cultural Experiential Learning Online. Contemporary Issues in Technology and Teacher Education [Online serial]. 3(2). Available: http://www/citejournal.org/vol3/iss2/socialstudies/article1.cfm

9. Merryfield, M. M. (2001). Moving the Center of Global Education: From Imperial World Views that Divide the World to Double Consciousness, Contrapuntal Pedagogy, Hybridity, and Cross-Cultural Competence. In W.B. Stanley (Ed.), Critical Issues in Social Studies Research for the $21^{\text {st }}$ Century. (pp. 179-207). Greenwich, CT: Information Age Publishing.

10. Merryfield, M. M. (2000). Using Threaded Discussion in Graduate Courses in Social Studies and Global Education. Theory and Research in Social Education 28(4), 502-526.

11. Merryfield, M. M., and A. Wilson. (2005). Social studies and the world: Teaching global perspectives. Silver Spring, MD: NCSS Bulletin 103.

12. Montgomery, K., Gottlieb-Robles, B., \& Larson, G. O. (2004). Youth as e-citizens: Engaging the digital generation. Washington, DC: Center for Social Media.

13. Risinger, C. F. (2006). Teaching about International Issues, Geography, and Multiple Points of View Using the Internet. Social Education, 70(1), 34-36.

14. RoperASW (2006). National Geographic - Roper Public Affairs 2006 Global Geographic Literacy Survey. Retrieved September 2, 2007 from http://www.nationalgeographic.com/roper2006/pdf/FINALReport2006GeogLitsurvey.pdf

15. RoperASW. (2002). National Geographic - Roper 2002 Global Geographic Literacy Survey. Retrieved September 2, 2007 from http://www.nationalgeographic.com/geosurvey/download/RoperSurvey.pdf

16. Seikaly, Z.A. (2001). At Risk of Prejudice: The Arab American Community. Social Education 65(6), 349-351.

17. Tye, K.A. (1999). Global Education as a Worldwide Movement. Orange, CA: Interdependence Press.

18. Zhao, Y., Hoge, J.D. (2006). Countering Textbook Distortion: War Atrocities in Asia, 1937-1945. Social Education 70(7), 424-430. 